\title{
How long should dinner take? Measuring expected meal duration for restaurant revenue management
}

\author{
Sheryl E. Kimes \\ School of Hotel Administration, Cornell University \\ Jochen Wirtz \\ NUS Business School, National University of Singapore \\ Breffni M. Noone \\ PhD Candidate, School of Hotel Administration, Cornell University
}

\begin{abstract}
KEYWORDS: service duration, expected service duration, revenue management, restaurant management

Restaurants have two strategic levers for revenue management: duration control and demand-based pricing. Reducing dining times, especially during peak periods, can add considerable revenue for the restaurant. Managing meal duration, however, can be far more complex than manipulating the price. This paper examines dinner duration expectations for a casual restaurant using an adaptation of a price sensitivity measurement tool, naming it 'Time Sensitivity Measurement' or TSM. TSM is then used to derive the expected dining time, the optimal and indifference duration points. The results show that there is a relatively wide spread of acceptable dining duration times.

Furthermore, the optimal and indifference points were significantly shorter than the mean expected dining time, suggesting that many restaurants may be able to shorten dining duration significantly (some 20 per cent in this present study) without compromising customer satisfaction.

Furthermore, the paper explores whether demographic variables have an impact on time preferences and finds only nationality effects to be significant. Specifically, North Americans and Asians have similar duration expectations, while Europeans preferred a significantly longer dining time.
\end{abstract}

\section{INTRODUCTION}

Restaurants have two strategic levers for revenue management: Duration control and demand-based pricing (Kimes and Chase, 1998; Kimes et al., 1998). One of the foremost duration control tools is to 
reduce customer dining time. If dining time can be reduced during busy periods, the number of customers served and profitability will increase. If customers feel rushed, however, satisfaction will decrease and the restaurant may lose future business. The key question is how much dining time can be reduced before customers feel rushed and satisfaction decreases. Meal duration is a function of three elements: Wait time, service time and consumption time. While research has been conducted on wait time and service response time, no study has addressed the total expected duration of a meal experience. This paper first examines the relationship between time and consumer behaviour and then proposes a model for the measurement of time sensitivity. It then presents the results of a pilot study that tested this measurement instrument.

\section{BACKGROUND OF THE PROBLEM}

\section{Restaurant revenue management}

Restaurant revenue management can be defined as selling the right seat to the right customer at the right price and for the right duration (Kimes et al., 1998). The determination of 'right' entails achieving both the most revenue possible for the restaurant and also delivering the greatest value to the customer. Without that balance, revenue management-type practices will in the long term alienate those customers who feel that the restaurant has taken advantage of them (Wirtz et al., 2001). Revenue management, or yield management, is commonly practised in the hotel and airline industries. Companies implementing revenue management report increases in revenue of 2-5 per cent over the results of prior procedures (Hanks et al., 1992; Smith et al., 1992).

Restaurant operators have two main strategic levers that they can use to manage revenue, namely, price and meal duration (Kimes and Chase, 1998; Kimes et al., 1998). Price is a fairly obvious target for manipulation, and many operators already offer price-related promotions to augment or shift peak-period demand (eg early-bird specials, special menu promotions, and happy hours for low-demand periods, and minimum cover charges or higher-priced menu items during peak periods). More sophisticated manipulations of price include day-part pricing, day-of-week pricing and price premiums or discounts for different types of party size, tables and customers (Kimes and Wirtz, 2002).

Managing meal duration is a bit more complicated. One of the difficulties of implementing revenue management in restaurants is the fact that their explicit unit of sale is a meal (or event) rather than an amount of time, although one could argue that the true measure of the restaurant's product is 
time (Kimes et al., 1998). While one can estimate a likely mean length for that meal, the actual duration is not set. By comparison, implementing revenue management is much easier for the hotel, airline, cruise-line and car-rental businesses, because they sell their service for an explicitly contracted amount of time. Restaurants rarely sell tables for a fixed amount of time, and most restaurants seem reluctant to broach this topic with customers. Moreover, North American restaurateurs cannot even rely on the practice of charging for the cover, which is common in many European countries.

One of the stumbling blocks to the successful implementation of restaurant revenue management is the struggle that restaurant operators have in developing internal methods of managing meal duration. In the context of managing meal duration, one should not think only of reducing diners' average meal length. Quite often the factor interfering with revenue management is the variability in meal lengths, and not just their duration. These issues can be addressed by, for example, streamlining the service-delivery process, changing reservation policies, redesigning menus, and pacing service processes and making them more efficient (Sill, 1991; Kimes et al., 1998; Kimes et al., 1999; Sill and Decker, 1999). Although customer dining time can be reduced, the issue of how customers will react to the reduction must be addressed (Kimes et al., 1999).

Reduced dining times can have considerable revenue potential during high demand periods. Consider a restaurant with 100 seats, a $\$ 20$ average bill, a one hour average dining time and a busy period of four hours per day. During busy periods, defined as those when customers are waiting for a table, a decrease in dining time can increase the number of customers served and the associated revenue. Under current conditions, the restaurant could theoretically serve 400 customers (240 minutes/60 minutes6100 seats) and obtain a revenue of $\$ 8,000$ (400 customers $6 \$ 20$ average bill). If the average dining time could be reduced to 50 minutes, the potential number of customers served would increase to 480 ( 240 minutes/50 minutes6100 seats) and the potential revenue would increase to $\$ 9,600$, an increase of 20 per cent (Kimes, 1999). The question of how customers would react causes restaurant operators to approach time decreases with caution.

\section{Time}

The concept of time has been studied in a wide variety of disciplines including economics, psychology, sociology, home economics and cultural anthropology (Gross, 1987; Mosakowski and Earley, 2000). Historically, economists have viewed consumption as an instantaneous act that does not have a temporal duration (Linder, 1970). Some economists have challenged this notion by analysing 
consumption time (Becker, 1965), time pressure (Berry, 1979), and time value of information searches (Stigler, 1961). Psychologists have focused on time expenditure in terms of information acquisition and choice behaviour (Berlyne, 1957; Lanzetta and Kanareff, 1962), while sociologists and home economists have concentrated more on descriptive studies on how people allocate time (Foote, 1961; Hall and Schroeder, 1970; Kleemeier, 1961; Walker, 1969). Studies of time allocation are also prevalent in the consumer behaviour literature (Feldman and Hornik, 1981; Holbrook and Lehmann, 1981; Holman and Wilson, 1982; Hirschman, 1987; Robinson and Nicosia, 1991). Marketers have also focused on the value of time and the impact of waiting time on consumer behaviour (Jacoby et al., 1976; Guy et al. 1994; Leclerc et al., 1995).

All services fundamentally sell the use of time (Davies, 1994). Chetthamrongchain and Davies (2000) identify three types of time: duration (clock time); succession (a series of events); social time (discretionary time). Duration-related research has been dominated by research on wait times and has drawn on the concept of subjective time perception, fostered predominantly in the fields of psychology and cultural anthropology. Two key streams of research have developed in the waiting-time literature: The relationship between perceived and actual wait time and the corresponding impact on customer satisfaction and perceptions of service quality (eg Dube'-Rioux et al., 1989; Davis and Vollmann, 1990; Katz et al., 1991; Price et al., 1995; Taylor, 1994; Hui and Tse, 1996; Tom and Lucy, 1997; Pruyn and Smidts, 1998; Lee and Lambert, 2000; Casado Dias and Mas Ruiz, 2002) and the management of customers' waiting experiences (eg Maister, 1985; Haynes, 1990; Jones and Peppiatt, 1996).

While it is evident that the studies to date have addressed the concept of time from a number of perspectives, no study has explicitly examined how long customers think a service encounter should last. Such research would have considerable value to restaurant operators and to other services in which customers implicitly purchase time.

While consumers typically try to minimise time spent in routine service encounters, they implicitly purchase time for services such as restaurants (perhaps with the exception of most quick service restaurants), golf, movies and many other leisure activities. For example, a significant proportion of golfers believe that a round of golf takes too long (Sterba, 2000). A savvy golf course operator could use this information to design a golf course and playing experience which would better meet customer preferences. Similarly, consider the film industry. Most movies last between 90 and 120 minutes. Movies less than 90 minutes may be considered too short, and customers may feel that they are not receiving their money's worth. Conversely, movies over 150 minutes may be considered too long, and consumers may choose not to view the movie. 
Restaurants experience the same problem. If customers think the meal experience takes too long, they may choose not to patronise a restaurant. A number of studies have shown that service delays, an antecedent of excessive dining duration, can have a negative impact on the customer satisfaction and their perception of service quality (Dube'-Rioux et al., 1989; Carmon et al., 1995; Tom and Lucy, 1997). Similarly, if customers believe the meal experience is too short, they may feel shortchanged or rushed, and may not return to the restaurant. The expected dining duration is affected by a number of variables including the type of restaurant, the reason for dining (special occasion, entertainment, routine) and the characteristics of the diners (nationality, age, income, frequency of dining out and amount of free time). For example, consider a couple that decide to dine out for their anniversary. They select what they perceive to be the nicest restaurant in town and expect to make an evening of the meal. If they go to the restaurant and dinner only takes an hour, they may feel shortchanged.

In sum, the broad objective of this research is to understand customer expectations of meal duration better and to develop a tool for measuring the optimal meal duration. By understanding these expectations, managers can modify and improve the design of their service encounters, and improve customer satisfaction. In the context of restaurant revenue management, an understanding of the optimal meal duration can help managers to determine how much dining time can be reduced while still maintaining customer satisfaction.

\section{METHOD}

\section{Measuring service encounter duration expectations and their sensitivity}

Research has shown that perceptions of time differ among individuals (Ballard and Seibold, 2000). The four basic methods for measuring time perception include verbal estimation, production, reproduction and method of comparison (Allan, 1979). In verbal estimation, the experimenter presents an event, and the subject gives a verbal estimate of its duration. For example, the experimenter might make the respondents wait and ask them to estimate the length of the wait. In production, the experimenter states the duration of the interval in clock time, and the subject produces that interval. For example, the experimenter might state that the waiting time is five minutes, and the subject will attempt to produce a five-minute wait. With reproduction, the subject reproduces the temporal interval presented by the experimenter. For example, the experimenter would make the subject wait for five 
minutes and then ask them to reproduce a wait of the same duration. Finally, with the comparison method, the experimenter presents two temporal intervals in succession, and the subject has to make a judgment of relative duration. For example, the experimenter would present a two-minute wait and a three-minute wait and ask the subjects to judge which wait was longer. While most early research on time perception was non-theoretical with the subject's responses being treated as direct estimates of perceived duration, quantitative models were subsequently developed (Creelman, 1962; Thomas and Weaver, 1975).

Other than studies on waiting time, there is little evidence of time perception measurement studies in a service environment context. Tom and Lucy (1997) focused on the measurement of perceived waiting time in a supermarket environment, while Lee and Lambert (2000) addressed perceived wait time in a cafeteria queue. In both of these studies, customers' perceptions of time were measured by verbal estimation and compared with actual wait times. While those studies focused on duration as a function of wait time, to the best of the authors' knowledge, no research has yet been conducted that addresses the consumers' perceptions of acceptable duration as a function of both wait and service times. This lack of research on the measurement of expected length of service encounters caused us to consider other areas of study, particularly that of how much customers think a service should cost.

Price sensitivity measurement (PSM) (Gabor and Granger, 1966; Shaw, 1992; Lewis and Shoemaker, 1997) has been used by a variety of companies to help determine customer price sensitivity and optimal pricing points. Price sensitivity measurement is survey based and consists of analysis of the response to four questions.

(1) What price would you consider to be high?

(2) What price would you consider to be so high that you would not purchase the service/product in the future?

(3) What price would you consider to below?

(4) What price would you consider to be so low that you would question the quality of the service/product?

The cumulative distributions of responses are graphed and used to determine the price indifference point, the optimal price point, the indifferent point percentage and the range of acceptable prices. The price indifference point is defined as where the percentage of respondents who think the price is cheap 
equals the percentage of respondents who think the price is expensive. The optimal price point is defined as the point at which the percentage of respondents who think the price is too low equals the percentage of respondents who think that the price is too high. The optimal price point is where purchase resistance due to price is at its lowest. The indifference point percentage is defined as the cumulative distribution percentage at the indifference point with a low percentage indicating a high price consciousness and a high percentage indicating a diffuse price consciousness.

The indifference point and the optimal price point are compared with the actual price the company charges. If the price charged is lower than the optimal price point, the company can probably increase price without affecting customer satisfaction and demand, while if the price charged is higher than the optimal price point, the company should probably decrease price in order to increase revenue.

The same technique was adapted to time expectations and pretested, naming the adapted method TSM. Rather than being asked questions about price, respondents were presented with a typical service encounter and asked the following questions.

(1) How long would be a bit too long?

(2) How long would be so long that you would consider not returning?

(3) How short would be a bit fast?

(4) How short would be so fast that you would feel rushed?

Time sensitivity measurement can then be used to calculate the indifference time point and the optimal time point.

\section{Study description}

In an effort to test TSM for time preferences, a survey was conducted in which respondents were asked to evaluate the dining time for a dinner with friends at a casual restaurant. The survey consisted of the four time sensitivity measures of TSM, plus one question on how long the respondent expected such a meal to last (i.e. mean expectations) (see Figure 1 for all five questions).

Respondents were asked to specify a time between 20 and 100 minutes in 10- minute intervals. Finally, demographic questions on nationality, gender and frequency of dining out were included. 


\section{Sample}

The survey was administered in three classes at Cornell University and 134 responses were received. The sample consisted of approximately 48 per cent female and 52 per cent male respondents. The nationalities represented five different continents, with the majority coming from North America (71.6 per cent), Asia (18.7 per cent) and Europe (8.2 per cent). Approximately 18 per cent of the respondents went out for dinner less than once a week, 65 per cent went out once or twice a week, and 17 per cent went out three times a week or more.

\section{SURVEY RESULTS}

\section{Dining time expectations}

The expected dining time was 60.2 minutes, much higher than the time considered to be short (29.9 minutes) and too short (23.4 minutes). The average time considered to be long was 81.6 minutes, while that considered to be too long was 93.0 minutes (Figure 2). These findings indicate that casual restaurants have considerable latitude in managing dining time duration without upsetting customers.

Figure 1: Operationalisation of TSM

Assume you are going out to a restaurant for a casual dinner with friends.

1. About how long do you think a dinner should take?

$\begin{array}{lllllllll}20 & 30 & 40 & 50 & 60 & 70 & 80 & 90 & 100\end{array}$

2. How long would your dinner have to be before you thought it was taking a bit too long?
$20 \quad 30$
50
$\begin{array}{llll}60 & 70 & 80 & 90\end{array}$
100 Minutes

3. How long would your dinner have to be before you thought it was so long that you would never return to the restaurant?

$\begin{array}{llllllll}20 & 30 & 40 & 50 & 60 & 70 & 80 & 90\end{array} \quad 100$ Minutes

4. How short would the dinner have to be before you thought it was a bit quick?
20
$\begin{array}{llllllll}30 & 40 & 50 & 60 & 70 & 80 & 90 & 100\end{array}$

5. How short would the dinner have to be before you thought it was so quick that you would feel rushed?

$\begin{array}{lllllllll}20 & 30 & 40 & 50 & 60 & 70 & 80 & 90 & 100\end{array}$ 
Figure 2: Summary of dining time expectations

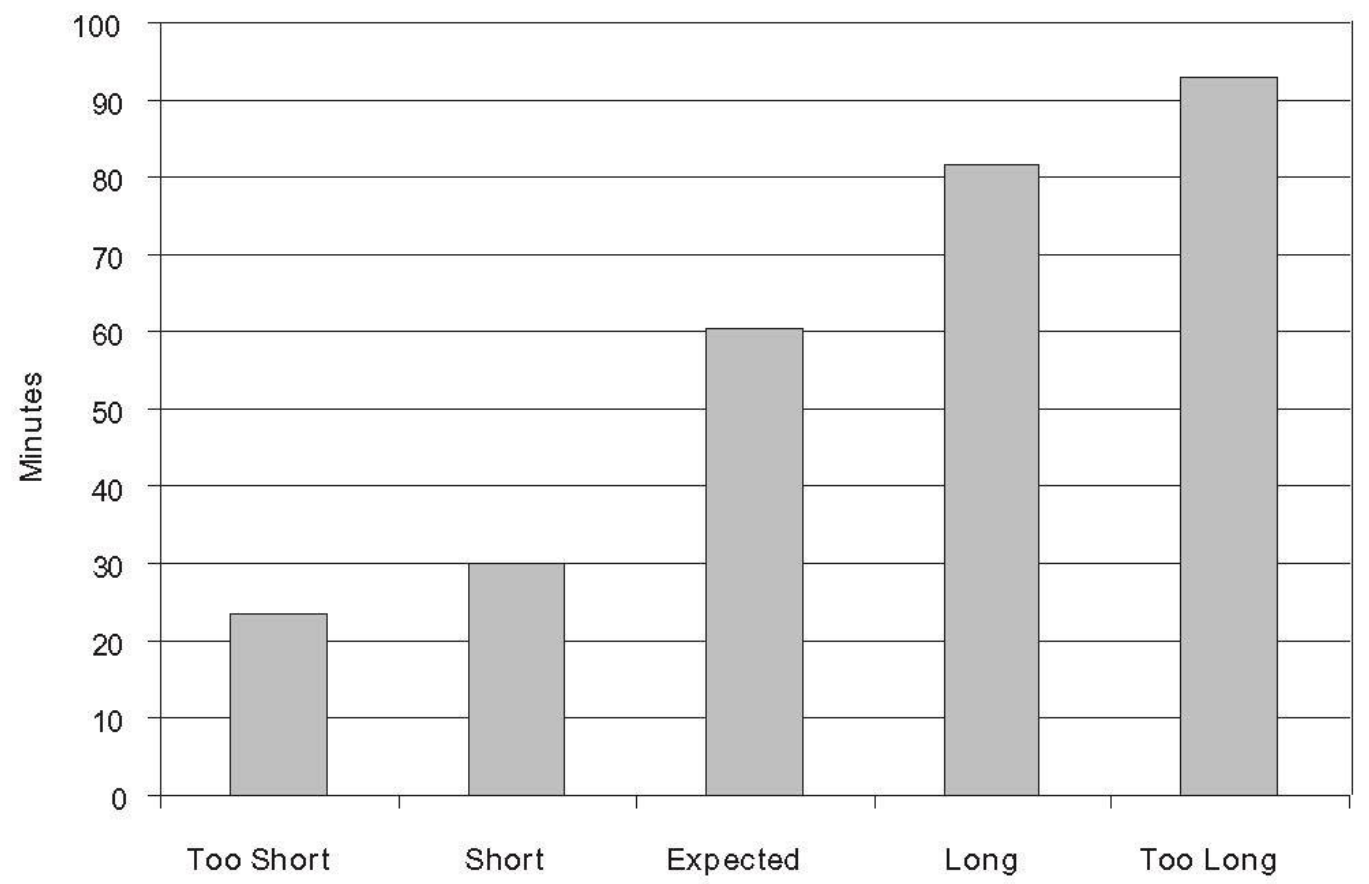

\section{Time sensitivity measurement}

Time sensitivity measurement used to develop a graph which included four lines: The cumulative percentage of respondents who thought the meal was short, the cumulative percentage who thought it was too short, the cumulative distribution of the percentage who thought the meal was long, and the cumulative distribution of those who thought it was too long (Figure 3).

The indifference point (percentage of respondents who thought it was short was equal to the percentage who thought it was long) was 48 minutes. The optimal point (percentage of respondents who thought it was too short was equal to the percentage of respondents who thought it was too long was 46 minutes). The optimal time point indicates the time where purchase resistance due to time is at its lowest.

The range of acceptable times is defined as the distance from the point of marginal shortness (intersection of the 'Short' line with the 'Not short' line) and the point of marginal length (intersection of the 'Long' line with the 'Not long' line). Acceptable times ranged from 30 to 90 minutes. These findings 
show that restaurants have considerable latitude in changing the time of the dining experience (Figure 4).

Figure 3: Indifference time point and optimal time point

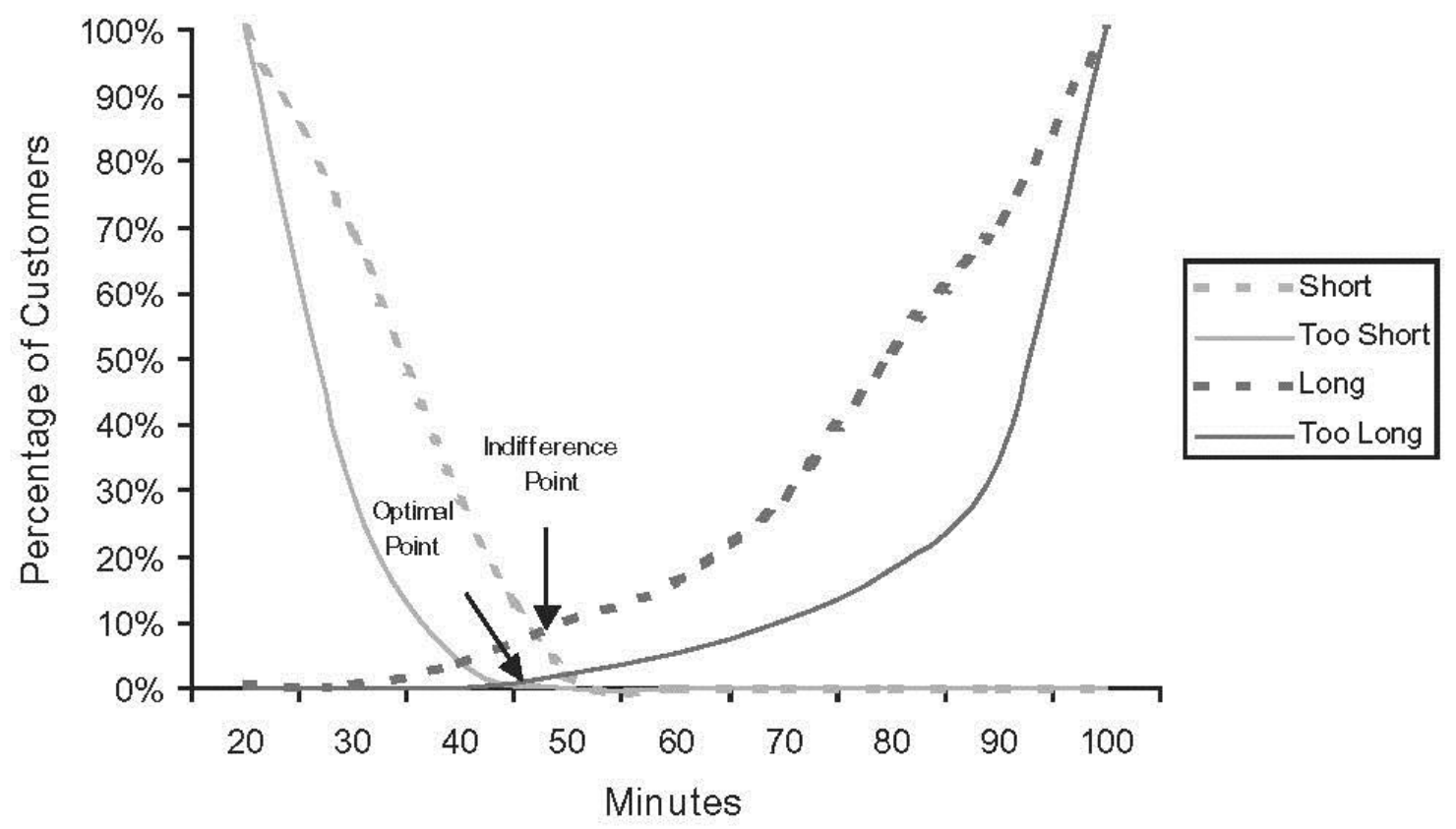

Figure 4: Range of acceptable times

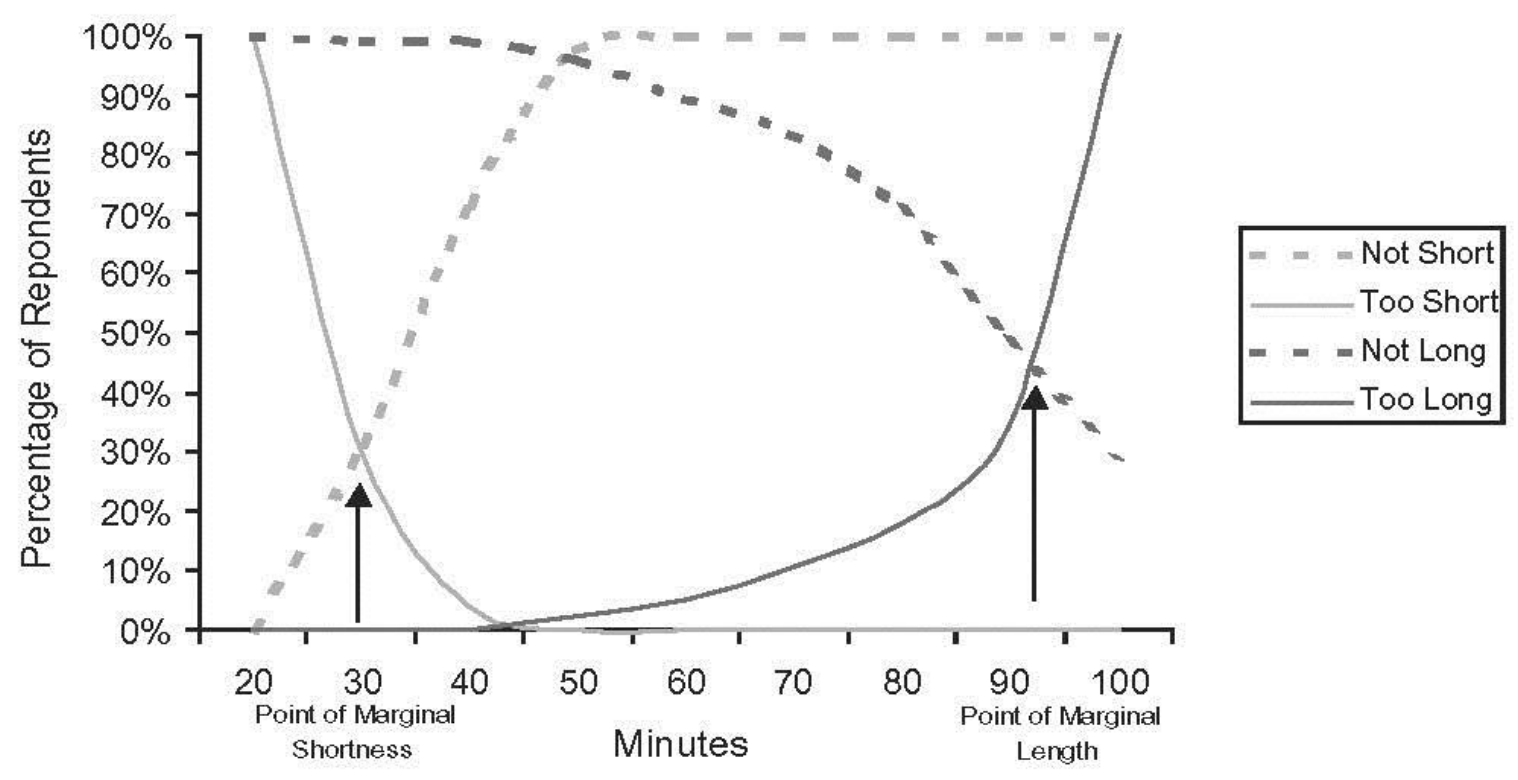




\section{Other findings}

A three-way multivariate analysis of variances (MANOVA) of demographic variables (nationality, gender and frequency of dining in restaurants) on the dependent variables of various time expectations was conducted. Only nationality showed a significant multivariate main effect (Wilks' Lambda $=0.78 ; \mathrm{F}(10$, $222)=2.92 ; p=0.002)$. The univariate main effects of nationality were either all significant at $p<0.05$, or marginally significant at $p<0.10$. No other multivariate main or interaction effect approached significance at the 0.10 level. Next, the findings by nationality are discussed in more detail.

\section{Expected dining time}

The mean expected dining time was 60.2 minutes but varied significantly by nationality as can be seen in Table 1 and Figure 5. Asian respondents had the shortest expected dining time of 57.2 minutes; North Americans averaged 59.0 minutes, while Europeans thought the meal should last about 77.3 minutes $(F=9.38, p<0.001)$.

Figure 5: Mean values by nationality

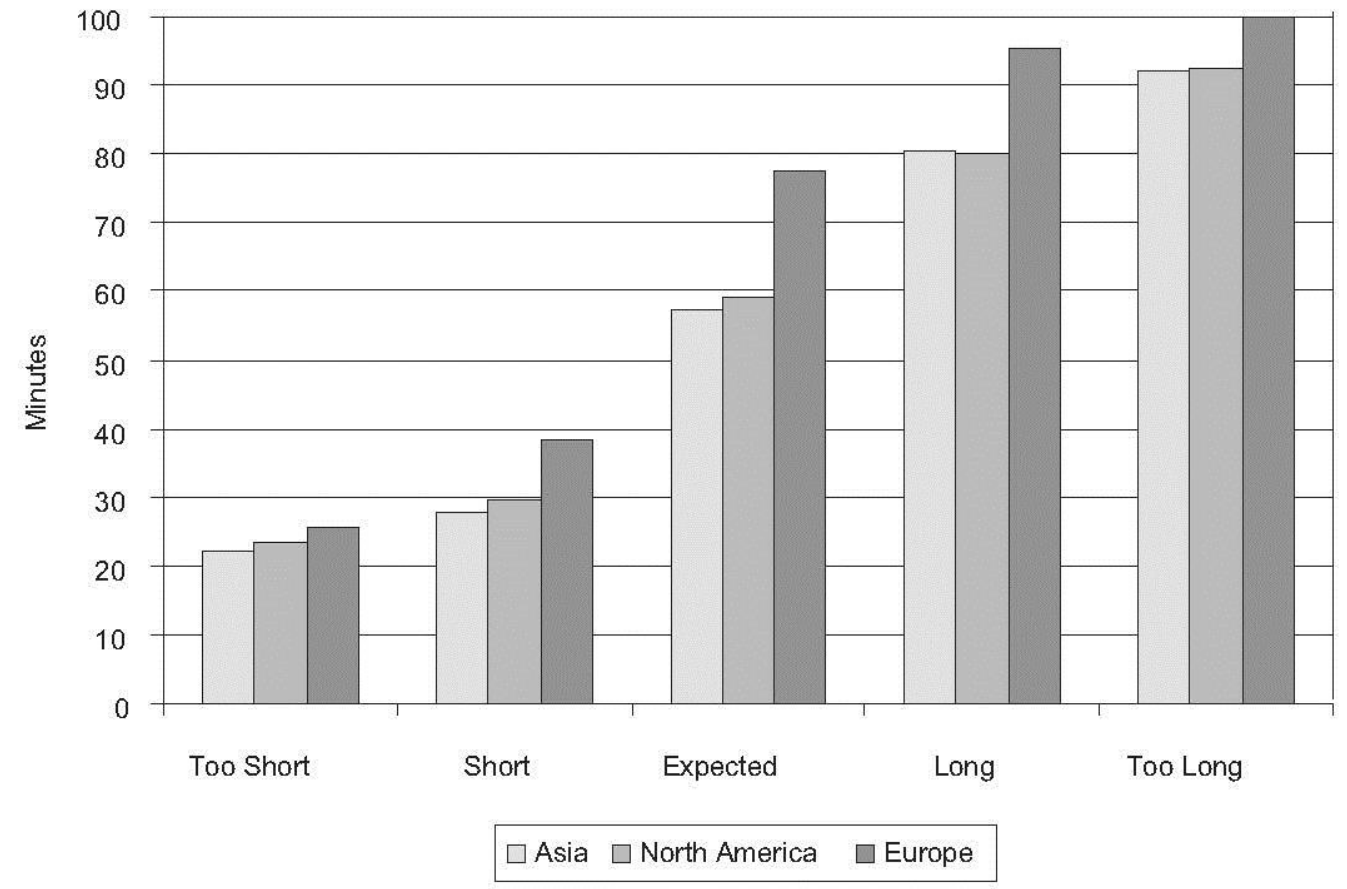


Table 1: Mean values by nationality

\begin{tabular}{|c|c|c|c|c|}
\hline & Means (STI & & & \\
\hline Dining time & Asia & North America & Europe & Total \\
\hline Expected $\star \star \star$ & $57.2(17.2)$ & $59.0(14.4)$ & $77.3(13.5)$ & $60.2(15.6)$ \\
\hline Short $\star \star \star$ & $27.6 \quad(6.6)$ & $29.5 \quad(8.3)$ & $37.3(6.5)$ & $29.9(8.2)$ \\
\hline Too short* & 22.0 & $23.4 \quad(5.8)$ & $25.5 \quad(5.2)$ & $23.4 \quad(5.5)$ \\
\hline Long $\star \star$ & $80.4(22.6)$ & $80.2(16.4)$ & $95.5 \quad(5.2)$ & $81.6(17.5)$ \\
\hline Too long $\star$ & $92.0(15.3)$ & $92.4(11.9)$ & $100.0 \quad(0.0)$ & $93.0(12.2)$ \\
\hline
\end{tabular}

$\star \star \star$ Significant at $\mathrm{p}<0.001$

$\star \star$ Significant at $\mathrm{p}<0.05$

$\star$ Marginally significant at $\mathrm{p}<0.10$.

\section{Short dining time}

The average 'short' dining time was 29.9 minutes. Again, the responses varied by nationality. Asians and North Americans had similar time responses (27.6 and 29.5 minutes, respectively), while Europeans specified a significantly longer time ( 37.3 minutes) $(F=7.05, p=0.001)$.

\section{Too-short dining time}

The average 'too-short' time was 23.4 minutes. Responses did not vary as much by nationality as for expected and short dining times, but was still in the same direction and reached marginal significance (Asians, 22.0 minutes; North Americans, 23.4 minutes; Europeans, 25.5 minutes; $F=2.51, p=0.09$ ).

\section{Long dining time}

The average dining time considered 'long' was 81.6 minutes. Responses varied significantly by nationality. Asians and North Americans had similar responses ( 80.4 and 80.2 minutes, respectively), while Europeans specified 95.5 minutes $(F=3.63, p=0.03)$.

\section{Too-long dining time}

The average time considered to be 'too long' was 93.0 minutes. As for the 'too short' dining time, the responses for 'too long' varied by nationality but only reached marginal significance (Asians, 92.0 
minutes; North Americans, 92.4 minutes; Europeans, 100 minutes; $F=2.88, p=0.06)$. There may, however, have been a ceiling effect, as all European ticked the longest duration option of the scale (ie 100 minutes). Thus, it can be reasonably assumed that, with a wider scale range, the difference in means for Europeans and the other nationalities would have been greater and the effect more highly significant.

\section{SUMMARY AND CONCLUSIONS}

Price sensitivity measurement was adapted for use with service encounter duration expectations and sensitivity. Time sensitivity measurement can be used to determine the indifferent and optimal duration of a service encounter. Previous research has not addressed customer time or duration expectations. If managers can understand better customer expectations of the time a service encounter should take, they can improve their service delivery system to meet customer needs. In addition, restaurant operators who implement revenue management can use TSM to determine the limits on dining time reduction.

It was found that the average dining time in casual restaurants (this study context) could be decreased by approximately 20 per cent without a decrease in customer satisfaction. This has a major impact on restaurant revenue during peak demand periods. If average dining time can be decreased by 20 per cent, the expected revenue during peak periods can be increased by some 25 per cent. Even if the restaurant must increase labour costs or incur other expenses, the financial impact can be considerable.

Even with knowledge of customer dining time expectations, restaurant operators must still be cautious as to how they achieve the time reduction. Evidence suggests that customers are more willing to accept (or not notice) decreases in time at the beginning or end of a meal, but may be upset if they felt rushed during the main part of the meal.

Furthermore, it was found that consumer expectations of dining time vary by nationality. Asians and North Americans had similar time expectations, while Europeans specified significantly longer times.

The increased revenue associated with reduced dining duration must be balanced against the increased costs associated with obtaining that time reduction. Meal duration can be decreased by streamlining the service delivery process, by deploying more labour or by redesigning the menu. While some customers may wish to linger over coffee, for instance, managers might be surprised at how often the hold-up in turning a table is the restaurant's own approach to service and server inattention to 
customer needs. Managers can also train employees to respond to customers' apparent wishes regarding the length of the meal. In the authors' experience, small drops in meal duration can be achieved with very little cost, but reduction of more than 10 minutes may be accompanied by more significant cost increases in labour and information technology.

\section{LIMITATIONS AND FURTHER RESEARCH}

This pilot study has several weaknesses, listed below.

(1) Only one type of restaurant and one type of dining experience were studied.

(2) A convenience sample was used.

(3) The top end of the time scales may have been insufficient, and it is highly likely that a ceiling effect was encountered.

The ceiling effect could be observed for European respondents, who all ticked the highest possible response (i.e. 100 minutes) on the 'too long' scale. Had a scale with longer time periods been provided, it can be reasonably assumed that the differences observed between Europeans, Americans and Asians would have been more pronounced and more highly significant.

Finally, the verbal estimation method was used for testing service encounter duration sensitivity. Other methods, including perhaps production, reproduction and method of comparison (Allan, 1979) or even field experiments could be explored in future work to test for robustness of the findings across measures and methods. The authors plan first to validate the TSM scale and then refine this research with an international study, which includes several types of restaurants (fine dining, casual, quick service) and dining occasions (special, nonspecial). In addition, research on customer reaction to when and how dining duration is reduced will be studied.

\section{ACKNOWLEDGMENTS}

The authors would like to acknowledge the support and feedback of Sunmee Choi, Dennis Reynolds and Alex Susskind of the Cornell University School of Hotel Administration, and gratefully acknowledge the excellent assistance provided by our research student Chua Hsiao Wei from the NUS Business School throughout this project. 


\section{REFERENCES}

Allan, L. G. (1979) 'The perception of time', Perception and Psychophysics, 26, 5, 340-354.

Ballard, D. I. and Seibold, D. R. (2000) 'Time orientation and temporal variation across work groups: implications for group and organisational communication', Western Journal of Communication, 64, 2, 218-242.

Becker, G. S. (1965) 'A theory of the allocation of time', The Economic Journal, 75, September, 493-517.

Berlyne, D. E. (1957) 'Conflict and choice time', British Journal of Psychology, 48, May, 116-118.

Berry, L. (1979) 'The time-buying consumer', Journal of Retailing, 55, Winter, 58-69.

Carmon, Z., Shantikumar, J. G. and Carmon, T. F. (1995) ‘A psychological perspective on service segmentation models: the significance of accounting for consumers' perceptions of waiting and service', Management Science, 41, 11, 1806-1815.

Casado Dı'as, A. B. and Ma' s Ruiz, F. J. (2002) 'The consumer's reaction to delays in service', International Journal of Service Industry Management, 13, 2, 118-140.

Chetthamrongchai, P. and Davies, G. (2000) 'Segmenting the market for food shoppers using attitudes to shopping and to time', British Food Journal, 102, 2, 81-101.

Creelman, C. D. (1962) 'Human discrimination of auditory duration', Journal of the Acoustical Society of America, 34, 582-593.

Davies, G. (1994) 'What should time be?', European Journal of Marketing, 28, 8/9, 100- 113.

Davis, M. M. and Vollmann, T. E. (1990) 'A framework for relating waiting time and customer satisfaction in a service operation', Journal of Services Marketing, 4, 1, 61-69.

Dube'-Rioux, L., Schmitt, B. H. and Leclerc, F. (1989) 'Customers' reaction to waiting: when delays affect the perception of service quality', in Srull, T. S. (ed.) Advances in Consumer Research, Vol. 16, Association for Consumer Research, Ann Arbor, MI, 59-63.

Feldman, L. P. and Hornik, J. (1981) 'The use of time: an integrated conception model', Journal of Consumer Research, 7, March, 407-419.

Foote, N. N. (1961) 'Methods for study of meaning in use of time', in Kleemeier, R. W. (ed.) Age and Leisure: A Research Perspective into the Meaningful Use of Time, Oxford University Press, New York, 156-176.

Gabor, A. and Granger, C. W. J. (1966) 'Prices as an indicator of quality: report on an enquiry', Economica, 33, February, 40-48. Gross, B. L. (1987) 'Time scarcity: interdisciplinary perspectives and implications for consumer research', in Sheth, J. N. and Hirschman, E. C. (eds) Advances in Consumer Research, Vol. 2, JAI Press, New York, 1-54.

Guy, B. S., Rittenburg, T. L. and Hawes, D. K. (1994) 'Dimensions and characteristics of time perceptions and perspectives among older consumers', Psychology and Marketing, 11, 1, 35-56.

Hall, F. T. and Schroeder, M. P. (1970) 'Effects of family and housing characteristics on time spent on household tasks', Journal of Home Economics, 62, January, 23-29. 
Hanks, R. B., Noland, R. P. and Cross, R. G. (1992) 'Discounting in the hotel industry, a new approach', Cornell Hotel and Restaurant Administration Quarterly, 33, 3, 40-45.

Haynes, P. J. (1990) 'Hating to wait: managing the final service encounter', Journal of Services Marketing, 4, 4, 2027.

Hirschman, E. C. (1987) 'Theoretical perspectives of time use: implications for consumer behavior research', in Sheth, J. N. and Hirschman, E. C. (eds) Advances in Consumer Research, Vol. 2, JAI Press, New York, 5581.

Holbrook, M. B. and Lehmann, D. R. (1981) 'Allocating discretionary time: complementarity among activities', Journal of Consumer Research, 7, March, 395-406.

Holman, R. H. and Wilson, R. D. (1982) 'Temporal equilibrium as a basis for retail shopping behavior', Journal of Retailing, 58, 1, 61-68.

Hui, M. K. and Tse, D. K. (1996) 'What to tell consumers in waits of different lengths: an integrative model of service evaluation', Journal of Marketing, 60, April, 81-90.

Jacoby, J., Szybillo, G. J. and. Berning, C. K. (1976) 'Time and consumer behavior: an interdisciplinary overview', Journal of Consumer Research, 2, March, 320-339.

Jones, P. and Peppiatt, E. (1996) 'Managing perceptions of waiting time in service queues', International Journal of Service Industry Management, 7, 5, 47-61.

Katz, K. L., Katz, B. M. and Larson, R. C. (1991) ‘Prescription for the waiting-in-line blues: entertain, enlighten, and engage', Sloan Management Review, Winter, 44-53.

Kimes, S. E. (1999) 'Implementing restaurant revenue management: a five-step approach', Cornell Hotel and Restaurant Administration Quarterly, 34, 3, 16-21.

Kimes, S. E. and Chase, R. B. (1998) 'The strategic levers of yield management', Journal of Service Research, 1, 2, 156-166.

Kimes, S. E. and Wirtz, J. (2002) 'Perceived fairness of demand-based pricing for restaurants', Cornell Hotel and Restaurant Administration Quarterly, 43, 1, 31-38.

Kimes, S. E., Chase, R. B., Choi, S., Ngonzi, E. N. and Lee, P. Y. (1998) 'Restaurant revenue management', Cornell Hotel and Restaurant Administration Quarterly, 40, 3, 40-45.

Kimes, S. E., Barrash, D. I. and Alexander, J. E. (1999) 'Developing a restaurant revenue management strategy', Cornell Hotel and Restaurant Administration Quarterly, 34, 5, 18-30.

Kleemeier, R. W. (1961) 'Time, activity and leisure', in Kleemeier, R. W. (ed.) Age and Leisure: A Research Perspective into the Meaningful Use of Time, Oxford University Press, New York, 3-13.

Lanzetta, J. T. and Kanareff, V. T. (1962) 'Information cost, amount of payoff and level of aspiration as determinants of information seeking in decision making', Behavioral Science, 7, October, 459-473.

Leclerc, F., Schmitt, B. H., Dube' , L. (1995) 'Waiting time and decision making: is time like money?', Journal of Consumer Research, 22, June, 110-119. 
Lee, W. and Lambert, C. U. (2000) 'Impact of waiting time on evaluation of service quality and customer satisfaction in foodservice operations', Foodservice Research International, 12, 4, 241-254.

Lewis, R. C. and Shoemaker, S. (1997) 'Price sensitivity measurement: a tool for the hospitality industry', Cornell Hotel and Restaurant Administration Quarterly, 39, 2, 44-54.

Linder, S. B. (1970) The Harried Leisure Class, Columbia University Press, New York.

Maister, D. H. (1985) 'The psychology of waiting lines', in Czepiel, J. A., Solomon, M. R. and Suprenant, C. F. (eds) The Service Encounter, JAI Press, New York, 113-123.

Mosakowski, E. and Earley, P. C. (2000) 'A selective review of time assumptions in strategy research', Academy of Management Review, 25, 4, 796-812.

Price, L. L., Arnould, E. J. and Deibler, S. L. (1995) 'Consumers' emotional responses to service encounters: The influence of the service provider', International Journal of Service Industry Management, 6, 3, 34-63.

Pruyn, A. and Smidts, A. (1998) 'Effects of waiting on the satisfaction with the service: Beyond objective time measures', International Journal of Research in Marketing, 15, 4, 321-334.

Robinson, J. P. and Nicosia, F. M. (1991) 'Of time, activity and consumer behavior: an essay on findings, interpretations and needed research', Journal of Business Research, 22, 171-186.

Shaw, M. (1992) 'Positioning and price: merging theory, strategy and tactics', Hospitality Research Journal, 15, 2, 31-39.

Sill, B. (1991) 'Capacity management: making your service delivery system more productive', Cornell Hotel and Restaurant Administration Quarterly, 33, 1, 77-87.

Sill, B. and Decker, R. (1999) 'Applying capacity-management science: the case of Browns Restaurants', Cornell Hotel and Restaurant Administration Quarterly, 40, 3, 22- 30.

Smith, B. A., Leimkuhler, J. F. and. Darrow, R. M. (1992) 'Yield management at American Airlines', Interfaces, 22, 1, $8-31$.

Sterba, J. (2000) 'Golf is booming - except that it isn't, unless you count TV', The Wall Street Journal, 13th April, A1+.

Stigler, G. J. (1961) 'The economics of information', Journal of Political Economy, 59, June, $213-215$.

Taylor, S. (1994) 'Waiting for service: the relationship between delays and evaluations of service', Journal of Marketing, 58, April, 56-69

Thomas, E. A. and Weaver, W. B. (1975) 'Cognitive processing and time perception', Perception and Psychophysics, $17,4,363-367$.

Tom, G. and Lucy, S. (1997) 'A field study investigating the effect of waiting time on customer satisfaction', Journal of Psychology, 131, 6, 655-660.

Walker, K. E. (1969) 'Homemaking still takes time', Journal of Home Economics, 61, October, 621-624. 
Wirtz, J., Ho, J. P. T. and Patterson, P. G. (2001) 'Yield management: resolving potential customer and employee conflicts', The NUS Business School Research Paper Series, 2001-2026 (Mkt.), National University of Singapore. 